INTERNATIONAL JOURNAL OF RESEARCHES IN BIOSCIENCES, AGRICULTURE AND TECHNOLOGY

(C) VISHWASHANTI MULTIPURPOSE SOCIETY (Global Peace Multipurpose Society) R. No. MH-659/13(N) www.vmsindia.org

\title{
THE STUDY OF ELECTRODEPOSITED PBS THIN FILMS USING DOUBLE EXPOSURE HOLOGRAPHY INTERFEROMETRY TECHNIQUE
}

\author{
R. D Mane ${ }^{1}$, P. P Chikode 1 , B. M. Sargar ${ }^{1}$ and M. B. Dongare ${ }^{2}$ \\ 1Jaysingpur College, Jaysingpur, Maharashtra, India \\ 2,Shivaji University, Kolhapur,Maharashtra, India \\ prashantchikode@gmail.com
}

\begin{abstract}
:
The $\mathrm{PbS}$ thin films have been deposited by electrode position on stainless steel substrate and $(\mathrm{CH} 3 \mathrm{COO}) 2 \mathrm{~Pb}$ and $\mathrm{Na2S} 2 \mathrm{O} 3$ of an aqueous bath. The solutions of different normality were used with complexing agent EDTA. Double Exposure Holographic Interferometry (DEHI) technique is used for studying surface deformation of stainless steel substrate which was exposed for different intervals of time. It is observed that stress changes with concentrations. It is noticed that number of fringes goes on increasing with concentration. This effect is due to increase in thickness of $\mathrm{PbS}$ thin films deposited on stainless steel substrate. We have also measured the mass of deposited $\mathrm{PbS}$ thin films. These films were characterized and optimized by using optical absorption and X-ray diffraction technique.
\end{abstract}

Keywords: $\mathrm{PbS}$ thin films, electrode position, Holographic interferometry X-ray diffraction, Optical absorption, Microstructure.

\section{Introduction:}

The advantage of Holographic Interferometry (HI) is that the distinct interference fringes appear even on a rough surface $[1,2]$. Also this method is used for time-shearing interferometry. [3, 4]. In certain H.I. can supply more information than is necessary when continuous comparison of surface displacements relative to an initial state. A wave front of an object can be compared, not with the reference wave front but with that of object itself in different states. These advantages made it easy to apply this technique to engineering problems. [5] $\mathrm{PbS}$ is a narrow band gap semiconductor material [6], which is very suitable for infrared detection application [7], this material is also used in many fields such as photography [8], $\mathrm{Pb} 2+$ ion selective sensors [9] and solar absorption [10]. Also, it has been used as photo resistance, diode lasers, humidity and temperature sensors, decorative and solar control coatings [11, 12]. The growth of conditions depends on these properties. Many researchers have contributed great in development and study of this material by various deposition processes such as electrodeposition [13], spray pyrolysis [14], photo accelerated chemical deposition $[12,15,16]$ microwave heating $[17,18]$, chemical bath deposition [19-23] and photochemical reactions [24]. Abundant literature is available on preparation and characterization of $\mathrm{PbS}$ thin films by various techniques. However, holographic interferometry technique has been first time used in $\mathrm{PbS}$ thin films. For the study of surface deformation of a stainless steel substrate after deposition of $\mathrm{PbS}$ thin film by electrode position we used the DEHI technique. This technique is sufficient to form a permanent record of relative surface displacement occurring after a fixed interval of time. The reconstructed image would be covered by interference fringes [25]. It is possible to investigate all changes in solid bodies, which are due to the form and quality of their surface [26].

\section{Material and Methods:}

1. Experimental set up: - PbS thin films were cathodically electrodeposited from aqueous solution containing different concentrations on stainless steel substrate, where EDTA was used as a complexing agent in the bath in order to control the rate of reaction. The different preparative parameters of the deposition were studied and optimized. All depositions were carried out in an unstirred condition and at room temp. (i.e.3000K). The cathodic polarization curves for different solutions of $\mathrm{PbS}$ are plotted and shown in Fig. 1(a) and 1(b). It is observed that the nature of curves is very broad and diffuse indicating that deposition of $\mathrm{PbS}$ occurs in large potential region. The films were deposited at constant potential versus Saturated Calomel Electrode (SCE). We have taken the (CH3COO) $2 \mathrm{~Pb}$ and Na2S2O3 with EDTA of different concentrations in double distilled water. The front side of stainless steel substrate was kept open and unwanted area of substrate was covered with insulating tape. Electrolytic cell [27] consists of a glass vessel, which is $30 \mathrm{ml}$ glass beaker fitted with wooden plate holder as shown in Fig.2. The stainless steel plate acts as a working electrode, a carbon plate and Saturated Calomel Electrode (SCE) as auxiliary and reference electrodes respectively. Before each deposition the working electrodes were ultrasonically cleaned for one minute, degreased in a acetone and thoroughly rinsed with double distilled water. The X-ray diffraction (XRD) pattern of the film was taken with the help of a Philips X-ray machine (PW-710) using CuKi i target as shown in Fig.3. The film deposited potentiostatically on FTO coated glass substrate to study optical absorption in the range of wavelength 350-850 mm, which was carried out using UV-VISNIR spectrophotometer (Hitachi model 330).

\section{Result and Discussion:}

2.1 Double Exposure Holographic Interferometry (DEHI): - The stainless steel substrate immersed in a solution for electrode position, is used as an object. Initially, the single hologram is recorded with exposure time of five seconds on holographic plate without any deposition. The reduction potential is applied across the electrodes due to which thin film of $\mathrm{PbS}$ was deposited on to the substrate and then the second exposure was taken after 5 second in both cases on same photographic plate. The 
holographic plate was processed (Kodak 8E 75 HD) and replaced in reference wave path. The reconstructed image of substrate was observed which shows the fringes that are localized on its surface where the film is deposited. We have prepared the solutions of different concentrations and deposition time, varied from $10 \mathrm{sec}$. to $40 \mathrm{sec}$. and holograms were recorded by conventional two beam off-axis technique [28-30] these are shown in Fig. 3. The plot of mass deposited against time of deposition is shown in Fig.4. This graph gives the information about the rate of mass deposited in unit time. 2.2 Measurement of stress, thickness of thin film: - The simple non-destructive technique for the quantitative measurement of stress in thin films by the use of DEHI technique is reported by Magill and Young [31]. The stress to the stainless steel substrate is given by the relation [32] and reported in Table No.1 (1) Where, $\mathrm{S}=$ stress in dynes $/ \mathrm{cm} 2$, $\mathrm{ts}=$ thickness of substrate, $\ddot{i} \#=$ deflection of the substrate equal to $4 i ̈ \neg / 2, Y s=$ Youngâ€ $€^{\mathrm{TM}_{\mathrm{S}}}$ modulus of substrate, $1=$ length of the substrate on which the film is deposited, $\mathrm{tf}=$ thickness of film. After recording of hologram, the object is illuminated with a beam making angle $\ddot{i} \pm 1$ with the normal and hologram is recorded in mean direction $\ddot{i} \pm 2$ during reconstruction. The reconstructed image has a superimposed fringe pattern corresponding to a displacement [d] of the surface [33] in normal direction and is given by, (2) Where, $n=$ total number of fringes, $\ddot{i}\urcorner=$ wavelength of light $\ddot{i} \pm 1, \ddot{i} \pm 2=$ angles that are sufficiently small So that, (3) After counting the relevant number of fringes directly from the hologram, we have determined the displacement of a point on the surface of the object i.e. information of the object surface. The mass of the deposited film was determined by the weight different method. After plotting graph of mass deposited against the deposition time, the rate of deposition for above films have been calculated and presented in Table No.1. 2.3 X-Ray diffraction studies: - The structural identification of $\mathrm{PbS}$ film was carried out by using $\mathrm{x}$ rays diffraction in the range of diffraction angle $2 i \pm$ between 100 and 1000. It was found from XRD pattern, that the films were face centered cubic structure with preferred orientation along (200) plane as shown in Fig.5. The d-values of XRD reflection were compared with standard d-values taken from Joint Committee on Powder Diffraction on Standards (JCPDS) data (5-592). A simplified reaction scheme is that at the negative, cathodic potentials $\mathrm{Pb}$ EDTA 2reduces to $\mathrm{Pb}$ and at the positive, anodic potentials, $\mathrm{Pb}$ re-oxidises and reacts with sulfide ions. $\mathrm{Pb}$ EDTA $2-+\mathrm{H} 2 \mathrm{O}+2 \mathrm{e}-=\mathrm{Pb}(\mathrm{s})+$ EDTA 3-(aq.) $+\mathrm{OH}-\mathrm{Pb}(\mathrm{s})+$ HS â€" (aq.) + $\mathrm{OH}$ â€" (aq.) $=\mathrm{PbS}$ (s) $+\mathrm{H} 2 \mathrm{O}+2 \mathrm{e}-\mathrm{A}$ general reaction in cathode-electrodeposition involving ions $\mathrm{Mz}^{+}$in aqueous solution takes the form, $\mathrm{Mz}^{+}$. $\mathrm{nH} 2 \mathrm{O}+\mathrm{Ze}-\mathrm{M}+\mathrm{nH} 2 \mathrm{O}$ (4) It proceeds in following steps- (i) ionic transport (ii) discharge (iii) incorporation of atoms onto the cathode and (iv) nucleation and growth [34]. All these steps involved to complete electrodeposition of a metal depend upon preparative parameters such as deposition potential current density, deposition time, temperature of the bath etc. We have prepared firstly lead acetate thin film cathodically on to the cleaned stainless steel substrate using [0.1 M Pb (CH3COO) $2+0.1 \mathrm{M}$ EDTA) solution in aqueous medium. The chemical reduction reaction at the cathode in an aqueous solution $(\mathrm{pH}=$ 4) is as follows $\mathrm{a} €$ " $\mathrm{Pb}(\mathrm{CH} 3 \mathrm{COO}) 2 \mathrm{~Pb}+2 \mathrm{CH} 3 \mathrm{COO}$ (5) The decomposition of water in hydrogen and oxygen occurs according to following reaction, $2 \mathrm{H} 2 \mathrm{O}$ $+2 \mathrm{e}-2 \mathrm{H}++20 \mathrm{H}-1.0697 \mathrm{Vs}$ SCE (6) To measure $\mathrm{pH}$ before and after reaction was $\mathrm{pH}=6$. Thus from this mechanism it is concluded that electrodeposition from $\mathrm{Pb}(\mathrm{CH} 3 \mathrm{COO}) 2$ precursor solutions onto stainless steel leads to the formation of $\mathrm{Pb}$ film. Similarly sulphur film is electrodeposited from $0.1 \mathrm{M}$ $\mathrm{Na} 2 \mathrm{~S} 2 \mathrm{O} 3$ solution in aqueous medium $(\mathrm{pH}=6)$ is as follows. S2O (aq.) S + SO (aq.) (7) For the formation of $\mathrm{PbS}(\mathrm{pH}=8.5)$ thin film, these two solutions of $0.1 \mathrm{M}$ normality are mixed with appropriate ratio to form a coherent, adhesive thin film. The chemical reactions for these are, i) $\mathrm{Pb} 2++2 \mathrm{e}-\mathrm{Pb}$ (8) ii) $\mathrm{S} 2 \mathrm{O}$ (aq.) $\mathrm{S}+\mathrm{SO}$ (aq.) (9) iii) $\mathrm{S}+2 \mathrm{e}-\mathrm{S} 2-(10)$ iv) $\mathrm{Pb} 2++\mathrm{S} 2-\mathrm{PbS}-1.2 \mathrm{~V}$ vs SCE (11) Thus we get PbS thin film, which is uniform, dense and adherent to the substrate. For the sulfide formation, the thiosulfate $\mathrm{S} 2 \mathrm{O} 3$ 2- ions play the key role for the oxidation/reduction reaction. $\mathrm{Pb} 2++\mathrm{S}+2 \mathrm{e}-=\mathrm{PbS} 2 \mathrm{~Pb} 2++3 \mathrm{~S} 2 \mathrm{O} 2-3+$ $3 \mathrm{H} 2 \mathrm{O}=2 \mathrm{PbS}+4 \mathrm{SO} 2-3+6 \mathrm{H}+$ All chemicals were reagent grade or better. The $\mathrm{pH}$ values of all solutions were adjusted with EDTA. As shown in Fig. 6. The nature of plot gives the existence of the direct transitions. The band gap (Eg) is determined by extrapolating the straight portion on the energy axis which gives the band gap energy Eg and the values found to be $1.1 \mathrm{eV}$. The microphotograph of $\mathrm{PbS}$ thin film as shown in Fig.7. The mass of PbS deposited on substrate was measured using one pan semimicrobalance of least count $0.00001 \mathrm{gm}$ and entered in the table no.1. The density of $\mathrm{PbS}$ was taken from JCPDS data file [5-592]. The thickness of films were measured by weight difference method and entered in Table No.1. From the graph of mass of $\mathrm{PbS}$ thin film deposited versus time of deposition it is found that as time of deposition increases mass as well as stress decreases. The nature of curve is similar to the curve given by Campbell et.al.[38].v) 2 versus hvh $\alpha$ photon energy, Eg - band gap energy and $n$ is constant depending upon the kind of optical transition. Specifically $n$ is $1 / 2$ or $3 / 2$ for the transition being direct allowed and direct forbidden respectively. The variation of (vo - is constant, $h \alpha$ From this reaction mechanism it is concluded that electrodeposition resulted in the formation of $\mathrm{PbS}$ thin film. 2.4 Optical absorption studies: - The optical absorption provides a simple method to study the material concerning band structure of material, for $\mathrm{PbS}$ film. The nature of transition (direct /indirect) is determined by using the relation [35-37].

\section{Conclusion:}

DEHI technique is used for measurement of stress and thickness of thin film deposited on stainless steel substrate. It is observed that with the increase in the deposition time thickness of thin film is increased and the stress decreases. The slope gives the rate of deposition of $\mathrm{PbS}$ thin film. It is found that this rate increases with concentration. $\mathrm{PbS}$ thin film has been prepared by cathodic electrodeposition from aqueous bath. The estimated deposition potentials 
were $-1.6,-1.2$ and $-1.1 \mathrm{~V}$ for $0.05 \mathrm{M}, 0.1 \mathrm{M}$ and $0.15 \mathrm{M}$ respectively on stainless steel substrate and $2.1 \mathrm{~V}$ on FTO coated glass substrate of $0.1 \mathrm{M}$ versus SCE. The films were face centered cubic structure is confirmed by JCPDS data file. The comparison of $d-$ values with standard JCPDS data and optical absorption analysis suggested that the deposited films were $\mathrm{PbS}$. The direct band gap energy of $\mathrm{PbS}$ is $1.1 \mathrm{eV}$. The optical microphotograph of lead sulfide film reveals that the film is uniform, dense and adherent to the substrate.

\section{Acknowledgement:}

The authors are thankful to authorities U.G.C., New Delhi for sanctioning minor research project under XIth plan.

Table No.1.Observed data for PbS thin film

\begin{tabular}{|c|c|c|c|c|c|}
\hline $\begin{array}{c}\text { Conc. } \\
\text { of } \\
\begin{array}{c}\text { solutio } \\
\mathrm{n}\end{array}\end{array}$ & $\begin{array}{c}\text { Depositio } \\
\mathrm{n} \text { time (t } \\
\text { sec.) }\end{array}$ & $\begin{array}{c}\text { No. of } \\
\text { fringe } \\
\mathrm{s}(\mathrm{N})\end{array}$ & $\begin{array}{c}\text { Thicknes } \\
\mathrm{s} \mathrm{d}(\mu \mathrm{m})\end{array}$ & $\begin{array}{c}\text { Mass } \\
\text { deposite } \\
\mathrm{d}(\mathrm{mg})\end{array}$ & $\begin{array}{c}\text { Stress } \\
\text { Sx109 } \\
(\mathrm{dyne} / \mathrm{cm} \\
2)\end{array}$ \\
\hline & 10 & 3 & 0.9492 & 0.005 & 0.3555 \\
\hline $0.05 \mathrm{~N}$ & 20 & 4 & 1.2656 & 0.012 & 0.2666 \\
\hline & 30 & 5 & 1.5820 & 0.014 & 0.2133 \\
\hline & 40 & 6 & 1.8984 & 0.017 & 0.1778 \\
\hline $0.1 \mathrm{~N}$ & 10 & 4 & 1.2656 & 0.011 & 0.2666 \\
\hline & 20 & 5 & 1.5820 & 0.018 & 0.2133 \\
\hline & 30 & 6 & 1.8984 & 0.023 & 0.1778 \\
\hline & 40 & 7 & 2.2148 & 0.029 & 0.1523 \\
\hline & 10 & 5 & 1.5820 & 0.0083 & 0.2133 \\
\hline & 20 & 6 & 1.8984 & 0.0161 & 0.1778 \\
\hline & 30 & 7 & 2.2148 & 0.0213 & 0.1523 \\
\hline & 40 & 8 & 2.8476 & 0.0326 & 0.1185 \\
\hline
\end{tabular}

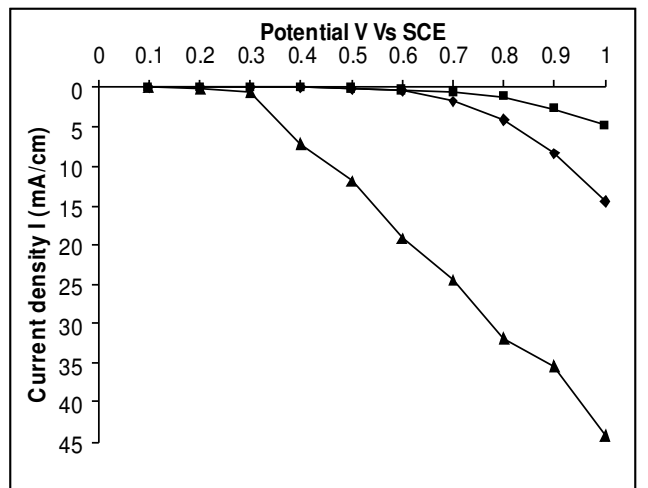

Fig. 1(a). Cathodic polarization curves for $\mathrm{PbS}$ thin film.

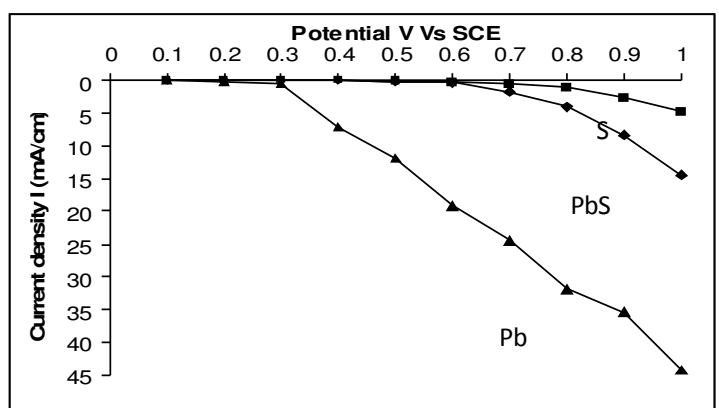

Fig.1(a). Cathodic polarization curves for electrodeposition of $\mathrm{PbS}$ thin

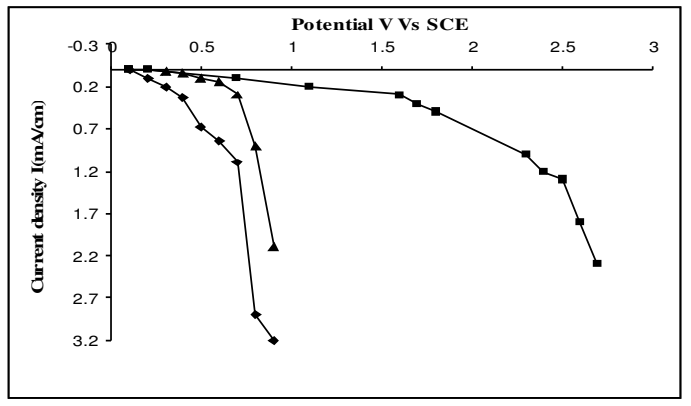

Fig. 1(b). Cathodic polarization curves for films FTO coated glass substrate. electrodeposition of $\mathrm{PbS}$ thin film.

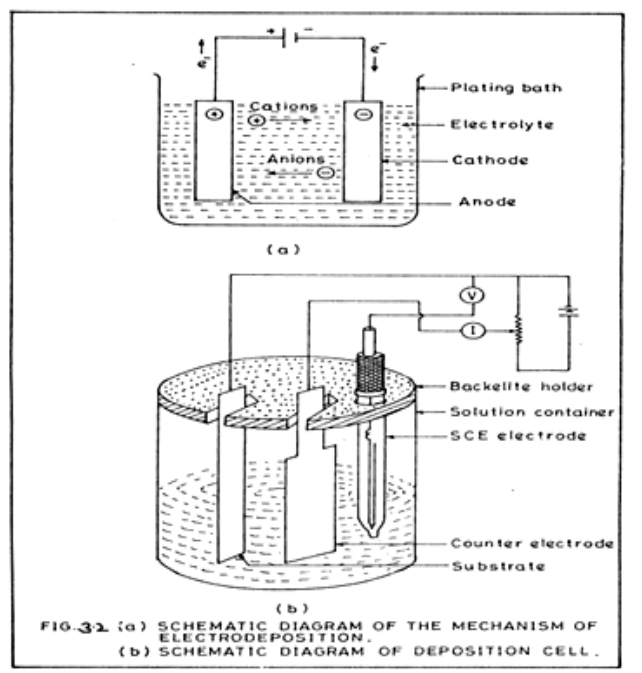

Fig.2. (a) Schematic diagram of the mechanis $m$ of electrodeposition.

(b) Schematic diagram of deposition cell.
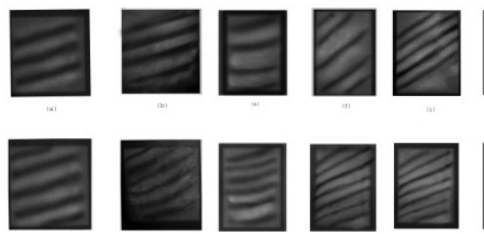

Fig.3.The Photographs of Interferograms of $\mathrm{PbS}$ thin films
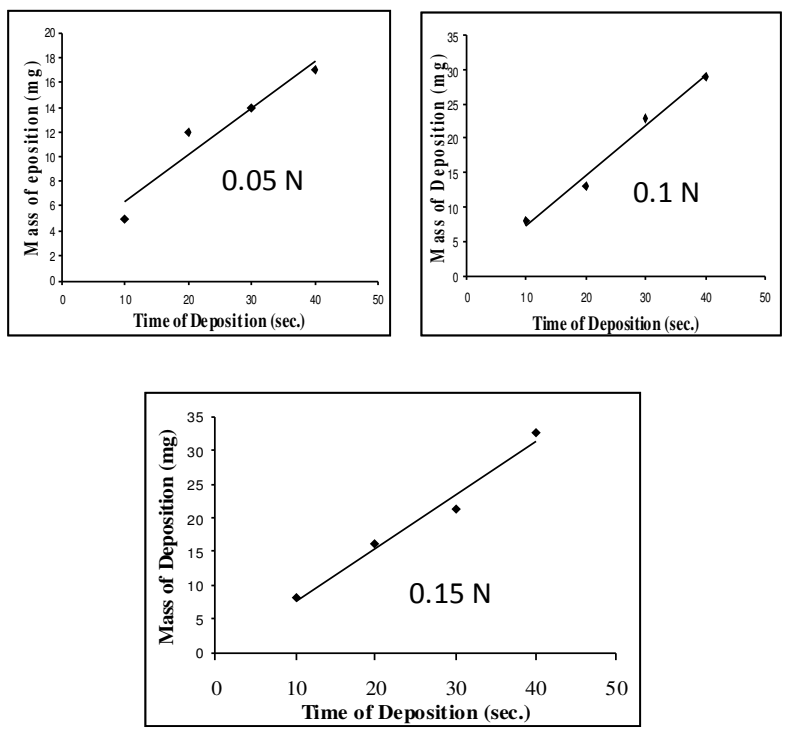
Fig. 4. Graph of mass deposited against time of deposition of $\mathrm{PbS}$ thin film.

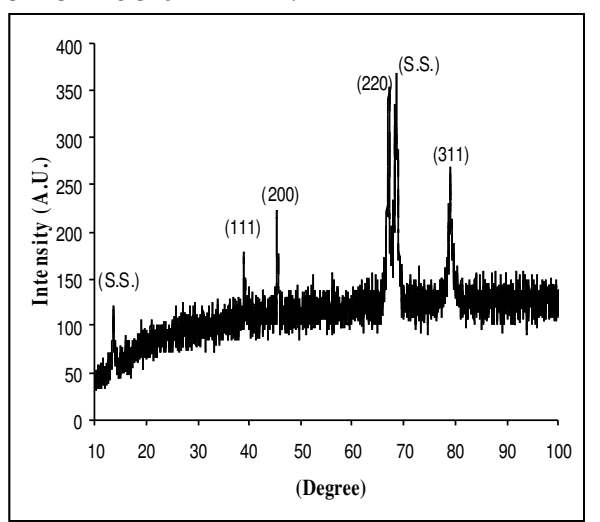

Fig.5. XRD pattern of $\mathrm{PbS}$ thin film

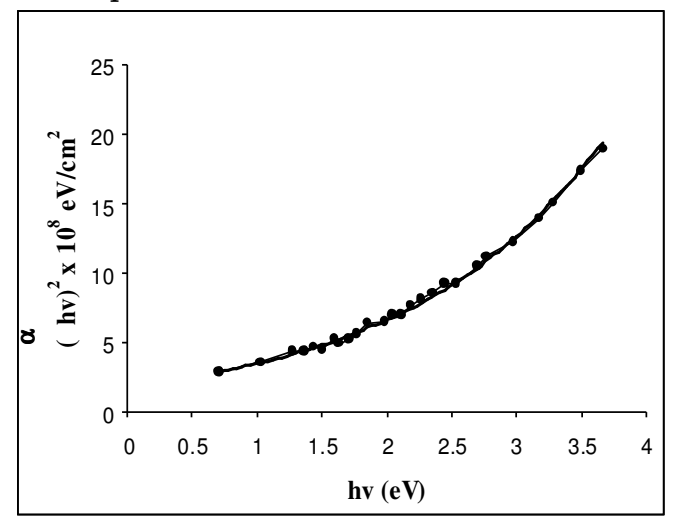

Fig.6. The variation of $(\alpha h v)^{2}$ versus $h v$ for $\mathrm{PbS}$ thin film.

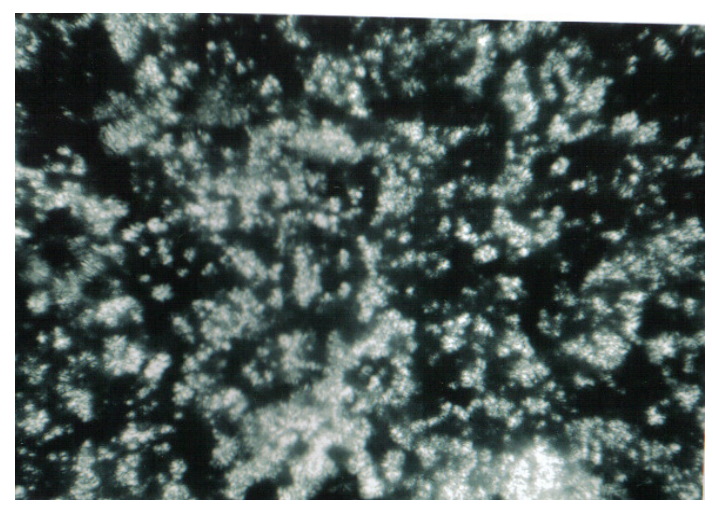

Fig.7. Microphotograph of $\mathrm{PbS}$ thin film.

\section{References:}

1) Collier R.J., Dohetry E.T. and Pennigton K.S., (1965), Appl Phys. Lett. 7, Pp. 223

2) Haines K.A., Hilderbrand B.P. (1966); Appl. Pt. 595 Pp.5.

3) Dongare M.B.,Thokale R.N and.Patil P.S, (2000), Asian journal of Phys. Vol.9, No.2, Pp.458-462

4) Fulari V.J., Kulkarni H.R. and Dongare M.B. (1996) , Jour. Opt., vol. 25 No.4, Pp.249-254.

5) Collier R.J., Burkharat C.B. and Lin L.H. (1971), Optical holography, (Academic press, New York), Pp.402-423.

6) Machol J.J., Wise F.W., Patel R.C., Tanner D.B., (1933) ,Phys. Rev. B48 Pp.2819.

7) Gademe P., Yagil Y., Scher D., J.Appl. (1989), Phys. 66 Pp.3019
8) Nair P.K., Gomezdaza O., Nair M.T.S, Adv. Mater., (1992), Opt. Electron. ,Pp.1139.

9) Hirata H., Higashiyama K., (1971), Bull. Chem. Soc. Jpn. 44 Pp. 2420.

10) Choudhuri T.K., Chatterjes S., (1992), Proceeding of the international conference on thermoelectronics, vol. 11., Pp.40.

11) Heana P., Cristina N., Violeta I., Indrea E., Bratu I., (1997) Thin solid films 307. Pp.240-244.

12) Nair P.K., Gareja V.M., Hermandez A.B., Nair M.T.S., (1991) J.Phys.D:Appl. Phys Pp. 241466-1472. 13) Sharon M., Ramaidh K.S., Kumar M., Spallart M.N., Clement L., (1997), Electoroanal. Chem. 436 PP.49-52.

14) Thangaraju B., Kaliannan P., Semicond., (2000), Sci. Technol. Pp.15849-853.

15) Pathan H.M., Lokhande C.D., (2004), Bull. Mater. Sci. vol. 27, No.2., Pp. 85-111

16) Zhao Y., Liao X. H., Hong J.M., Zhu J.J., (2004) ,Matter Chem. Phys. 87 Pp. 149-153.

17) Nascu C., Vomir V., Pop I., Ionescu V, Greeus R, (1996) Mater. Sci. Eng. B 41, Pp.235-240.

18) Larramendi E.M., Calzadilla O., Gonzalez-Arias A., Hemandez E., Ruiz J. Garcia, (2001), Thin solid films 389 Pp.301-306.

19) Pentia E., Pintilie L., Tivarus C., Pintilie I., Botila T., (2001), Mater. Sci Eng. B 80 Pp.23-26.

20) Joshi R.K., Kanjilal A., Sehgal H.K., (2004) Appl.Surf. Sci. Pp.22143-47.

21) Valenzuela J.J.. Jauregui, Bon R.R., MehdozaGalvan A., Sotelo M., (2003) ,Thin solid films 441 Pp.104-110.

22) Ichimura M., Narita T., Masui K., (2002), Mater. Sci and Eng. B 96 Pp. 296-299.

23) Stroke G.W., (1969), An introduction to coherent optics and Holography, Academic, New York,.Pp. 202.

24) Nassenstein H., (1966), Phys Lett. 21 Pp. 290.

25) Pawar S.H., Shinde V.N., (1993), Int. conf. on energy Environ and Electrochem, Karaikudi.

26) Leith E.N. and Upatnieks J.J., (1962), Opt Soc. Amer 5 ,Pp. 1123.

27) Leith E.N. and Upatnieks J.J. ,(1963), Opt Soc. Amer 53 Pp. 1377.

28) Leith E.N. and Upatnieks ,(1964) ,J.J. opt Soc. Amer 54 Pp. 1295.

29) Magill P.J and Young T, J. Vac. (1967), Sci, Techol. 4 Pp. 47.

30) Campbell D.S., (1963), Electron Reliab Microminiaturization, 2,Pp. 207.

31) Katzir Y. Friensam A A and Rav-Noyz, Applications of holography and Data Processing (1977),Pergamun Press, Oxford, New Yor), Pp. 279.

32) Pandey R.K., Sahu S.N. and Chandra S., (1966), 'Handbook of Semiconductor Electrodeposition, Marel Dekker, Inc. New York,Pp. 40.

33) Gaikwad N. S., Bhosale C. H., (2000), Mater. Chem. Phys. 62 pp. 242

34) Rajpure K.Y., Lokhande C.D., Bhosale C. H., (1997), Thin solid films.311 Pp.114.

35) Rajpure K.Y., Bhosale C. H., (2000), Mater. Chem. Phy. 62, Pp.169.

36) Campbell D. S. Maissel L. I and Glung R., (1970) , Handbook of thin film Technology., Mac. Grow Hill book. Company, New York, Pp. 12-39. 